УДК 621.391

\title{
ВЫЧИСЛЕНИЕ ПИК-ФАКТОРА СИГНАЛОВ МНОГОКАНАЛЬНЫХ СИСТЕМ С ОFDМ
}

\author{
БОНДАРЕВ Б. Н., КАБАК В. С.
}

Запорожский национальный технический университет, Украина, Запорожье, 69063, ул. Жуковского, 64

\begin{abstract}
Аннотация. Проведен анализ имеющихся в литературе методик и результатов по вычислению пик-фактора групповых сигналов многоканальных систем с использованием частотного уплотнения с ортогональными поднесущими (OFDM). Показана необходимость корректировки вычислений при использовании закона распределения Рэлея для огибающей узкополосного нормального случайного процесса.

Для вычислений предложен метод, основанный на теории выбросов случайных процессов. Произведены необходимые вычисления. Показано, что разброс результатов разных методов составляет 0,5-2,0 дБ по значениям пик-фактора и до 100 раз по значениям вероятности. Предпочтительным и точным методом является метод с использованием параметров нормального закона
\end{abstract}

Ключевые слова: уплотнение; средняя мощность; максимальная мощность; пик-фактор; закон распределения вероятностей; групповой сигнал

\section{1. ПОСТАНОВКА ЗАДАЧИ}

В последние годы все большее применение в многоканальных системах находит частотный метод уплотнения с ортогональными поднесущими OFDM (Orthogonal FrequencyDivision Multiplexing). К таким системам относятся перспективные системы мобильной связи, системы цифрового телевидения, системы широкополосного доступа. Число поднесущих частот (частотные каналы) в мобильной связи составляет около 200, в цифровом телевидении — около 2000 или 8000.

Достаточно полное изложение принципов OFDM, перечень первоисточников и краткие исторические сведения приведены в [1]. Впервые этот метод уплотнения использован в американской системе коротковолновой радиосвязи «Кинеплекс» (1958) [2, 3]. Американский патент на этот метод выдан в 1970 [4]. В 1971 предложено использование быстрого преобразования Фурье для операций модуляции и детектирования [5].

В [8] впервые введено понятие пик-фактора многоканального OFDM-сигнала, которое по мнению авторов не совсем корректно. В [9] приведено несколько иное определение пик-фактора.

В [10] проведен критический анализ используемой в [8] методики, предложена другая, адекватная методика определения пик-фактора многоканального сигнала, получены новые, уточненные результаты.

Целью настоящей работы являются определение пик-фактора сигналов в многоканальных системах с OFDM с помощью методики, основанной на теории выбросов случайных процессов, и сравнение результатов, полученных различными методами. 